Portland State University

PDXScholar

Civil and Environmental Engineering Master's

Project Reports

Civil and Environmental Engineering

2017

\title{
Impact of Speed on Vehicle Safety on Urban Arterial Roadways
}

Andrew C. Vosper

Portland State University

Follow this and additional works at: https://pdxscholar.library.pdx.edu/cengin_gradprojects

Part of the Transportation Engineering Commons

Let us know how access to this document benefits you.

\section{Recommended Citation}

Vosper, Andrew C., "Impact of Speed on Vehicle Safety on Urban Arterial Roadways" (2017). Civil and Environmental Engineering Master's Project Reports. 34.

https://doi.org/10.15760/CCEMP.1

This Project is brought to you for free and open access. It has been accepted for inclusion in Civil and Environmental Engineering Master's Project Reports by an authorized administrator of PDXScholar. Please contact us if we can make this document more accessible: pdxscholar@pdx.edu. 
Impact of Speed on Vehicle Safety on Urban Arterial Roadways

\author{
By \\ Andrew Vosper
}

A research project report submitted in partial fulfillment

of the requirement for the degree of

\author{
MASTER OF SCIENCE \\ IN \\ CIVIL AND ENVIRONMENTAL ENGINEERING
}

Project Advisor:

Dr. Christopher M. Monsere, PhD, PE

Portland State University

(C) 2017 


\section{ACKNOWLEDGMENTS}

I would like to acknowledge and thank my family (mainly my wife) who has helped me through everything.

To my project supervisor and advisor Dr. Christopher Monsere, thank you for your help and guidance throughout the years.

To the Portland State University Department of Civil and Environmental Engineering, the supportive and educational environment is what all schools need to aspire for. 


\begin{abstract}
Vehicle speed has long been one, if not the primary contributing factor to crashes, influencing both the probability and severity. Within the Portland metro area arterials have the highest serious crash rate per road mile and vehicle miles travelled. (Metro, 2012) The purpose of this research is to compile vehicle speeds along select arterial roadways within the Portland metro area and comparing it to applicable crash data. The roadway segment of SE Foster Road between SE $52^{\text {nd }}$ avenues and SE $82^{\text {nd }}$ avenues was selected, due to the simplicity of the physical as-built roadway properties along with available Bluetooth travel time data and Oregon Department of Transportation crash data.

The crash data is reported in one hour intervals, and the mean traffic speed was calculated to correlate to the crash data intervals. Crash types, causes, and severities were reviewed and compared vehicle speeds during the time of day and week. Negative correlating relationships between the crash types and vehicle speeds were determined, as most crashes occurred at speeds lower than the average mean. High traffic volume during peak travel times (3 PM to 6 PM) appears to be the primary contributing factor along the roadway segment. The second highest crash types are angle and turning maneuvers, both having a potential correlation to higher than average traffic speeds, but further review with detailed speed data at intersections would be required.

The roadway improvements currently proposed by the City of Portland, Bureau of Transportation aim to reduce the root causes for crashes along the corridor including implementation of a road diet; however, minor modifications to high risk intersections can be made to reduce severe crashes that are not currently identified in the plan.
\end{abstract}


TABLE OF CONTENTS

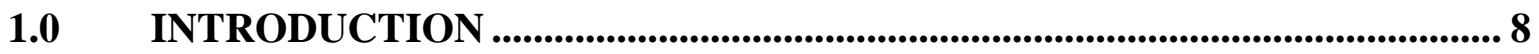

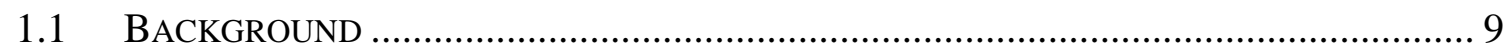

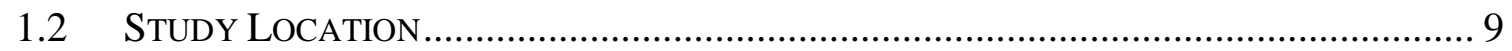

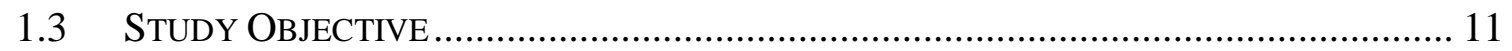

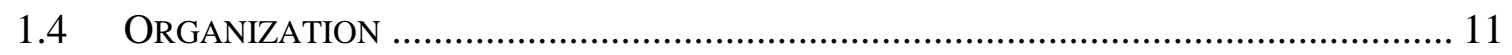

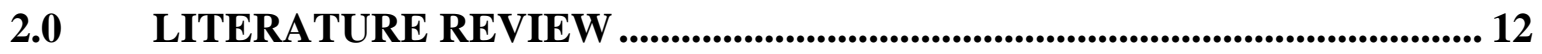

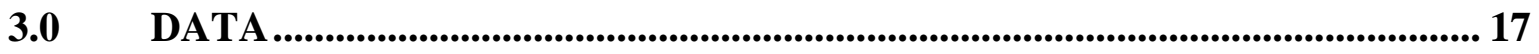

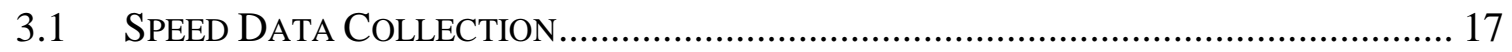

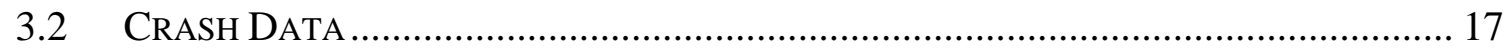

3.3 Data StATISTICAL CHARACTERIZATION AND ANALYSIS ......................................... 22

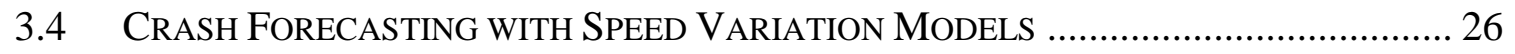

3.5 SE Foster RoAdWAy IMPROVEMENT Plan........................................................ 28

3.5.1 SE 52 ${ }^{\mathrm{ND}}$ AVE AND SE Foster RD INTERSECTION ANALYSIS.............................. 29

3.5.2 SE 72 ${ }^{\mathrm{ND}}$ AVE AND SE FosteR RD INTERSECTION ANALYSIS............................... 31

3.5.3 SE 80 ${ }^{\mathrm{TH}}$ AVE AND SE Foster Rd INTERSECTION ANALYSIS ................................ 32

4.0 CONCLUSIONS................................................................................................... 34

5.0 REFERENCES ...................................................................................................... 36 


\section{LIST OF TABLES}

Table 1 - Intersection Crash Count ................................................................................ 18

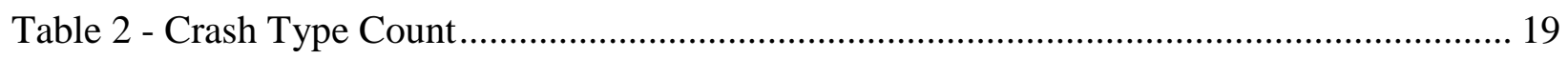

Table 3 - Primary Crash Cause Overview .......................................................................... 20

Table 4 - Crash Injury Severity Count and Description .................................................... 21

Table 5 - Correlation between Average Speed and Crash Count by Type ............................... 25

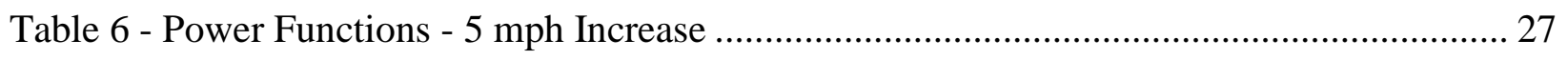

Table 7 - Power Functions - 5 mph Decrease ............................................................... 27 


\section{LIST OF FIGURES}

Figure 1 - SE Foster Road - Study Section Vicinity Map............................................................. 10

Figure 2 - SE Foster Road Study Location Overview .............................................................. 10

Figure 3 - Involvement Rate by Variation from Average Speed Day and Night (Solomon, 1964)

Figure 4 - Crash Involvement Rate by Deviation From Average Traffic Speed ............................ 14

Figure 5 - Nilsson's Power Models (R. Elvik, 2010) .......................................................... 15

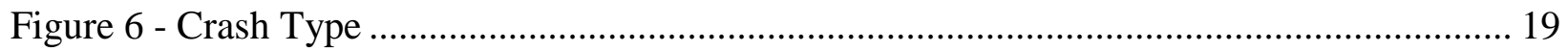

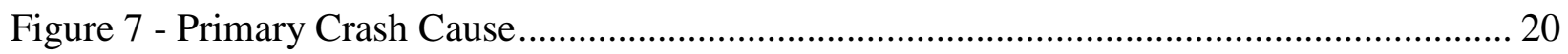

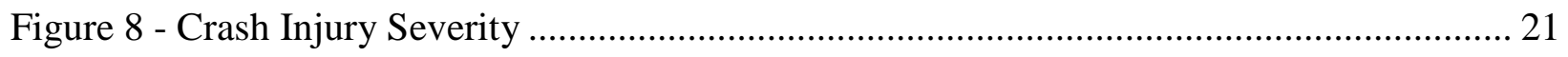

Figure 9 - Time of Day/Week vs. Average Vehicle Speed and Crash Count without Rear End . 22

Figure 10 - Crash Count at Deviation from Mean Speed ............................................................. 23

Figure 11 - Crash Count without Rear End at Deviation from Mean Speed ................................ 23

Figure 12 - Angle Crash Count at Deviation from Mean Speed .................................................... 24

Figure 13 - Backing Maneuver Crash Count at Deviation from Mean Speed ............................... 24

Figure 14 - Fixed Crash Count at Deviation from Mean Speed...................................................... 24

Figure 15 - Pedestrian Crash Count at Deviation from Mean Speed ............................................. 24

Figure 16 - Sideswipe Crash Count at Deviation from Mean Speed ............................................ 24 
Figure 17 - Overtaking Crash Count at Deviation from Mean Speed........................................ 24

Figure 18 - Turning Crash Count at Deviation from Mean Speed............................................. 24

Figure 20 - Crash Severity by Collision Type at Intersection with SE Foster.......................... 28

Figure 21 - SE 52 ${ }^{\text {nd }}$ Ave and SE Foster Rd Planned Intersection Improvements ...................... 30

Figure 22 - Aerial Photograph of SE 52 ${ }^{\text {nd }}$ Ave and SE Foster Rd Intersection ......................... 30

Figure 23 - SE 72 ${ }^{\text {nd }}$ Ave and SE Foster Rd Planned Intersection Improvements ...................... 31

Figure 24 - Aerial Photograph of SE 72 ${ }^{\text {nd }}$ Ave and SE Foster Rd Intersection ........................ 31

Figure $25-\mathrm{SE} 80^{\text {th }}$ Ave and SE Foster Rd Planned Intersection Improvements..................... 33

Figure 26 - Aerial Photograph of SE $80^{\text {th }}$ Ave and SE Foster Rd Intersection .......................... 33 


\subsection{INTRODUCTION}

Over the last few years various federal and state of Oregon entities have installed detectors at various locations throughout the Portland Metro Area. The purpose of these detectors is to collect vehicle, bicycle and pedestrian information so it can be interpreted and utilized to make informed project and policy decisions. One type of data collectors used on the roadways are Bluetooth detectors, which record the signal emitted from a Bluetooth enabled devices (typically cellular phones). The recorded signals are compared between multiple detectors along a roadway segment, from matching the Bluetooth device signal from two locations and travel time can be determined and vehicle speed derived. In regards the focus of this research project, the data collected from the Bluetooth detectors set up along arterial roadways in the Portland area, including but not limited to: Sandy Blvd., Broadway, $82^{\text {nd }}$ Ave, $122^{\text {nd }}$ Ave, Foster Rd, and Barbur Blvd. These urban arterial roadways service large volumes of traffic between collectors and local roads to highways. SE Foster Road was chosen as the primary focus of this research due to the data availability and simplistic roadway characteristics.

Vehicle speed in relation to crashes has very generic relationship "as speed increases, the time to react to emerging dangers is shortened, and the likelihood of successfully coping with the imminent crash situation decreases. Also, even after the driver reacts by braking, the braking distance of the vehicle is proportional to the square of pre-braking speed... But reality is much more complicated, both theoretically and empirically.” (Shinar, 1998) Understanding this basic theory, higher vehicle speeds leads to less reaction time and subsequently higher crash rates. Research by (Solomon, 1964) on rural highways concluded that "regardless of the average speed on a main rural highway, the greater the driver's deviation from this average speed, the greater his chance of being involved in an accident.” Utilizing these basic relationships between vehicle speed and safety (crashes), we can explore it to the urban arterial SE Foster Road data within Portland, Oregon and determine correlations (if any). The following information gives a detailed overview of the study objective, data collection, and analysis means and methods. 


\subsection{Background}

According to the Portland Bureau of Transportation speed kills. "Impairment, speed and dangerous behaviors contribute to $91 \%$ of deadly crashes in Portland... Wide, fast arterials with multiple lanes in each direction see a disproportionate number of traffic deaths.” (VisionZero, 2014) Speed is always a contributing factor to a vehicle crash, and will always be one since movement/velocity is needed between two entities in order to create an impact/crash. Various state and city entities have developed projects aiming at eliminating crash related fatalities and severe injuries within the Portland metro area. Speed as a behavior will be reviewed along the SE Foster Road and compared to applicable crash data to determine what characteristics are contributing the most to the urban arterial crashes.

\subsection{Study Location}

The study area is SE Foster Rd between 52nd and 82nd which is in Southeast Portland and is one of the city's main vehicular transit arteries. The urban segment of Foster Road runs diagonally NW/SE starting at the intersection of Powell Blvd \& SE 50th Ave extending to Interstate-205. Foster is considered a principal arterial, connecting the main metropolitan area to rural areas while at the same time providing a high degree of mobility to urban areas along the roadway. The study section is four-lanes, two each way, on-street parking segments, no dedicated bicycle lane, with five controlled intersections, four signalized pedestrian crossings and four nonsignalized pedestrian crossings. 35 miles per hour is the posted speed limit for the entire segment shown. 


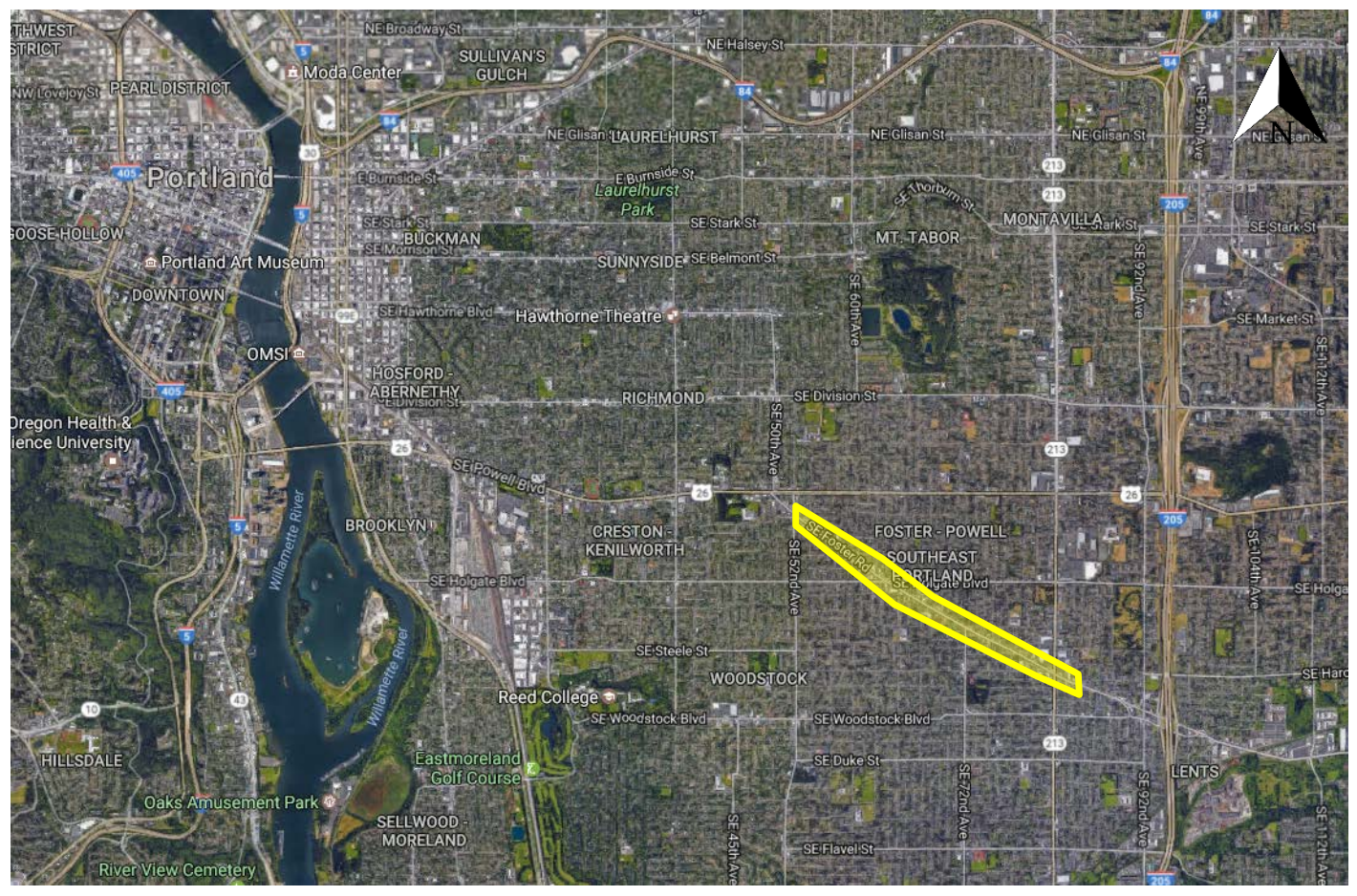

Figure 1 - SE Foster Road - Study Section Vicinity Map

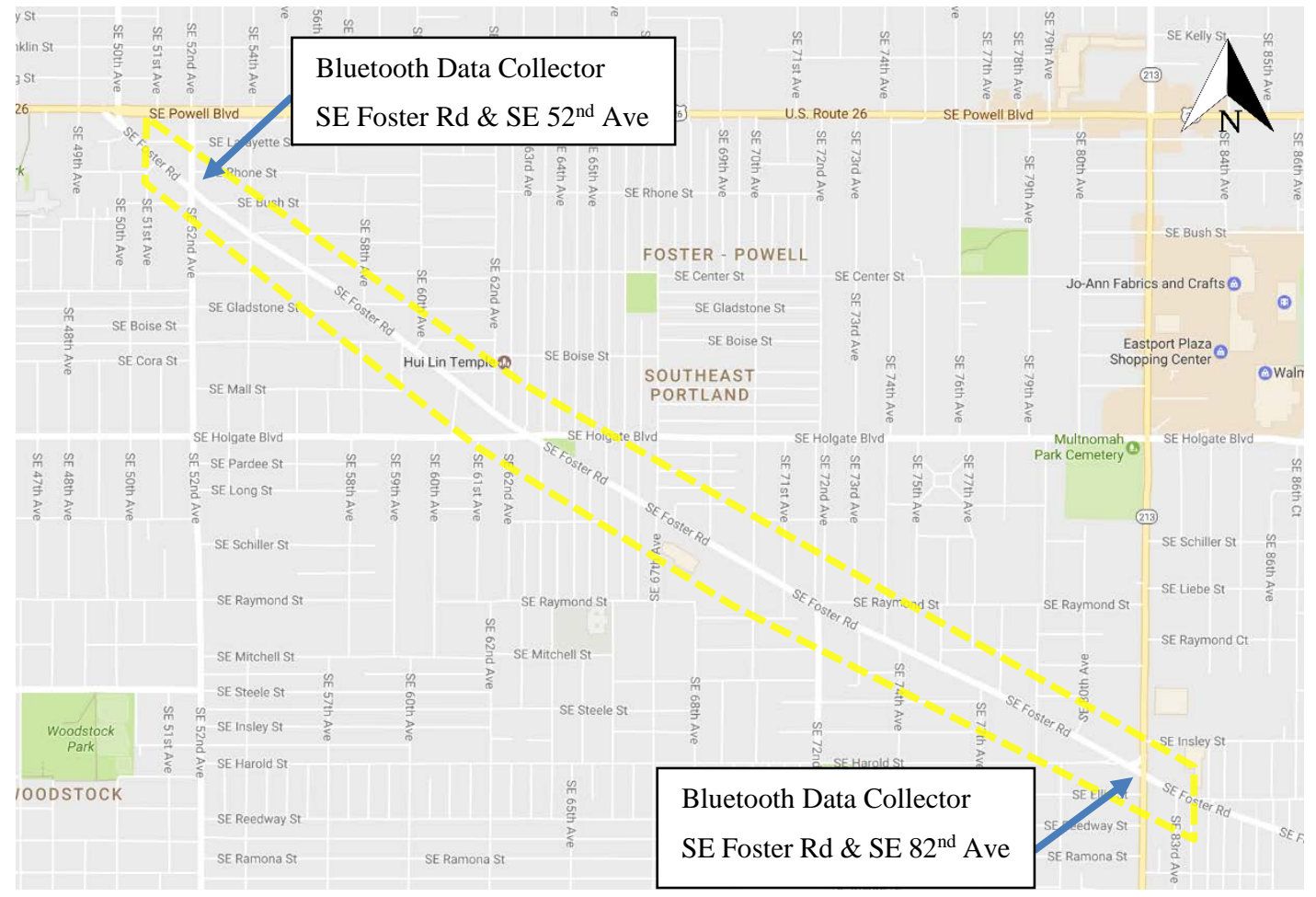

Figure 2 - SE Foster Road Study Location Overview 


\subsection{Study Objective}

The object of this research project was to determine vehicle travel speed along SE Foster Road between SE $52^{\text {nd }}$ and $82^{\text {nd }}$ avenues and cross-referenced against available crash data for the reported section of roadway. This allows us to:

1. Determine correlation (if any) to the average vehicle speed during a given hour of the day and vehicle incidents

2. Determine crash causes and locations, relate it to proposed roadway improvements

3. Project future crash estimates using power models

\subsection{Organization}

This research project is comprised of five different sections, including: introduction, literature review, data, conclusions, and references. The introduction goes over the basic overview of the study, study location and data types used. The literature review section has an overview of applicable studies that have been previously done that apply directly to the focus of this project.

The data section provides an analysis collected data sets, including:

- Crash types and summaries

- Speed data and analysis

- Statistical analysis between crash types and speed data

- Crash probability forecasting models utilizing power functions

- Recommended roadway improvements

The conclusion provides a summation of the information as well as it applicability to the studies noted in the literature review section. Finally, the references include a full list of the journals and reports utilized to provide knowledge and support for this research project. 


\subsection{LITERATURE REVIEW}

The influence of vehicle speed in regards to safety is common research topic; however, the determination of a crash occurring due to an increase in speed or a deviation from the mean vehicle speed along the roadway still does not have a finite answer. This literature review covers previous studies that have been made regarding vehicle travel speed and level of crash occurrence and severity. The primary search engine utilized was Google Scholar accessed through the Portland State Library using the keywords: speed, crash, arterial, and safety. The search results were reviewed and filtered to identify applicable articles and reports that pertain to this research project. Most of the available work reviewed pertained to highways; however, some articles had insight on urban arterial roadways using previous highway focused research methods.

Every vehicle crash is unique. Crash commonalities allow us to develop relationships in an attempt to determine cause and probabilities in order to reduce crashes and injuries altogether. William Haddon developed a matrix that is/can be directly applied to vehicle crashes, breaking the event into three different phases: pre-event, event, and post-event or in this case pre-crash, crash, and post-crash. (Haddon, 1980). Within this matrix, the vehicle speed factor occurs in both the pre-crash and crash events. Pre-crash includes the physical speed of the vehicle, the roadway speed limit, and additional factors that influence the probability of a crash occurrence. During the crash event, the speed of the vehicle has a major influence on the severity of the crash. Again, additional factors such as roadway, weather, vehicle performance, other vehicles (if any) conditions influence the outcome of the crash.

Solomon (1964) generated a U-shaped curve (Figure 2), correlating vehicle travel speed and crash involvement rate. The data came from $~ 10,000$ crash reports along 35 sections of a highway throughout various states in the United States. The research derived two key conclusions (1) increase in vehicle speed increases the risk of severity during a crash and (2) variation from the mean traffic speed results in higher crash involvement rates. Although there is a third key conclusion, being that (3) an increase in speed increases crashes, particularly single vehicle crashes. However, conflicts with additional research does not always support the third argument. 


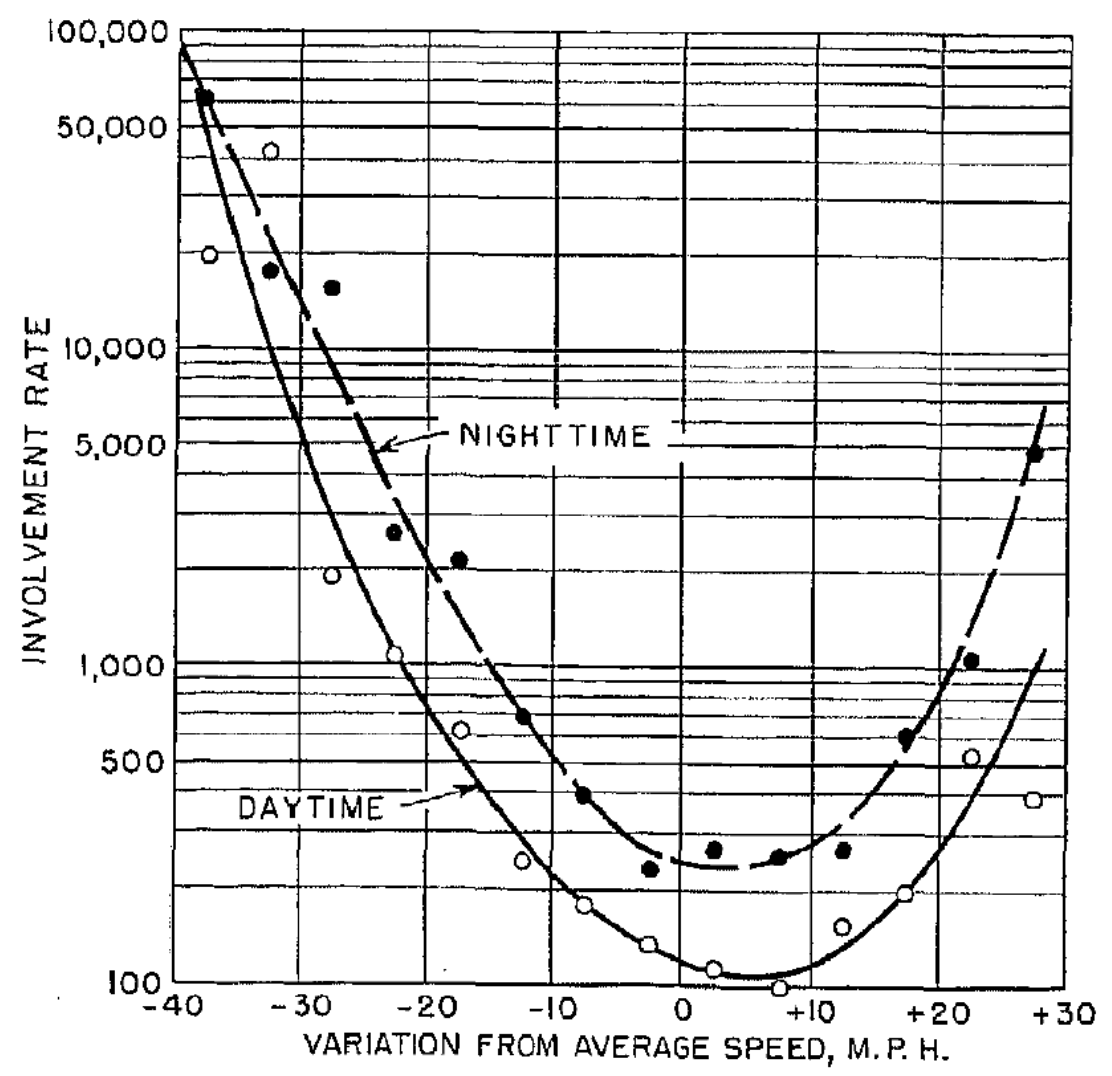

Figure 3 - Involvement Rate by Variation from Average Speed Day and Night (Solomon, 1964)

Additional research by Fildes et al. (1991) took Solomon's findings and tried to reproduce them for both rural and urban highways within Australia. The two urban arterial roadway segments where four lanes, undivided and had a posted speed limit of $60 \mathrm{~km} / \mathrm{h}$ or $37 \mathrm{mph}$ much like the Foster road segment being reviewed in this research project. The study developed a positive linear slope/relationship between deviation from average speed and crash involvement rate. This is plotted atop Solomon's curve. “Interpreted in this light, the U-shaped curve can be explained as follows: in a two-car following situation, slowing vehicles are more likely to be struck than fast vehicles because when they slow down, drivers behind them are often not immediately aware of the speed change, and thus slowing down reduces the headways of cars behind them." (Shinar, 1998) 


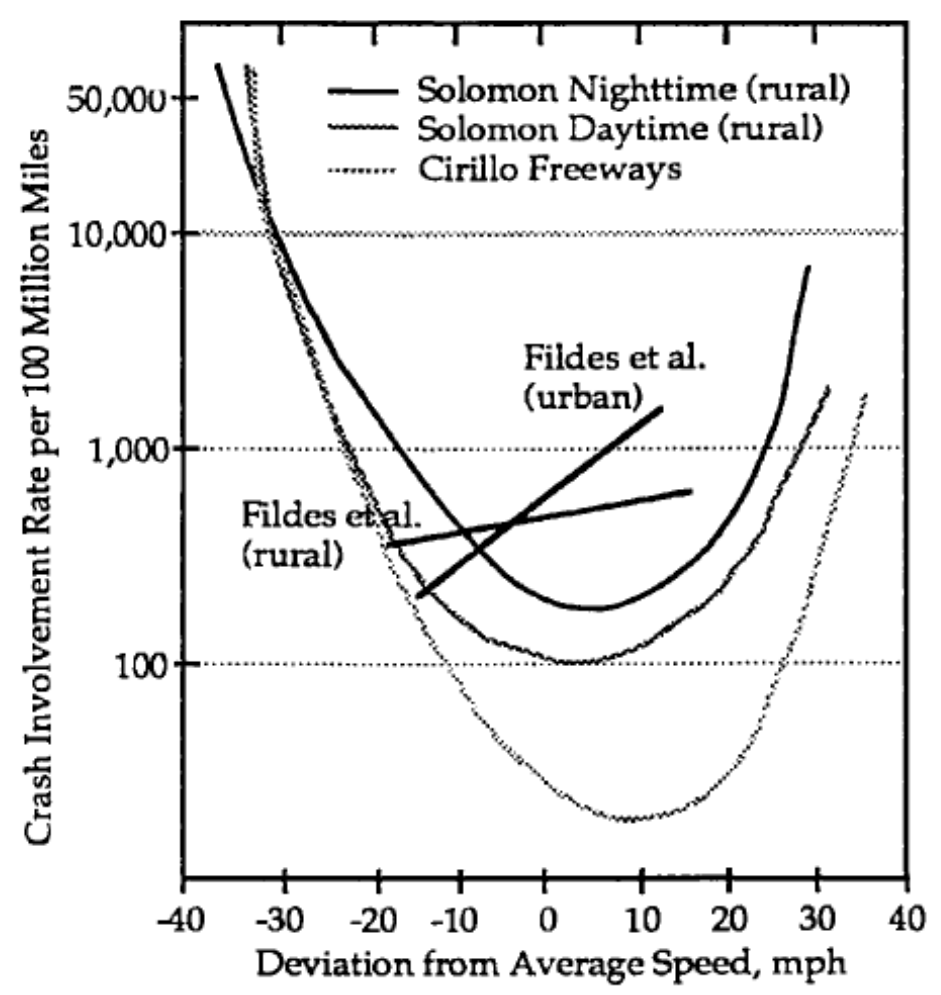

Figure 4 - Crash Involvement Rate by Deviation From Average Traffic Speed

Driver or vehicle characteristics were also determined for speeding motorists within Fildes et al. (1991). They concluded that on an urban roadway speeding drivers where likely to have one or more of the following:

- Young (inexperienced) driver (under 34 years) with a high crash history,

- High perception of what constitutes a safe travel speed,

- Drivers in vehicles less than 5 years old, and

- Business travelers (not on recreation journeys) who drive high weekly mileages.

These characteristics were obtained by both the trash data and a driver questionnaire. The traits listed previously cannot be readily substantiated given the information provided by the Bluetooth detectors within this research project. 
After the crash event, the severity of the crash is broken into various levels: fatal, serious casualty, and casualty crashes. To project out future crash events and their respective severities Nilsson (1981) developed power relationships connecting traffic speeds with roadway trauma. Figure 5 shows the formulas used to predict accidents and roadway trauma with an increase or decrease of the vehicle speed. Initially Nilsson's power functions shown were developed for rural highways and subsequent analysis by Elvik et al. (2004) applied meta-analyses to smooth out the power estimate for urban arterial roadways. The resulting power functions by Elvik et al. were determined that significantly lower than the initial power estimates developed for rural highways. The reduction in the power estimates was primarily related to the lower fatalities and serious injuries on urban arterials, associated with lower travel speeds. Additionally, it was also concluded that "a single speed parameter (mean or average) is not sufficient to represent the influence on casualty crashes due to the speed distribution on urban roads.” (R. Elvik, 2010)

$$
\begin{aligned}
& \text { Number of fatal accidents }=Y_{1}=\left(\frac{V_{1}}{V_{0}}\right)^{4} Y_{0} \\
& \text { Number of fatalities }=Z_{1}=\left(\frac{V_{1}}{V_{0}}\right)^{4} Y_{0}+\left(\frac{V_{1}}{V_{0}}\right)^{8}\left(Z_{0}-Y_{0}\right) \\
& \text { Number of fatal and serious injury accidents }=Y_{1}=\left(\frac{V_{1}}{V_{0}}\right)^{3} Y_{0} \\
& (3) \\
& \text { Number of fatal or serious injuries }=Z_{1}=\left(\frac{V_{1}}{V_{0}}\right)^{3} Y_{0}+ \\
& \left(\frac{V_{1}}{V_{0}}\right)^{6}\left(Z_{0}-Y_{0}\right) \\
& \text { Number of injury accidents }(\text { all })=Y_{1}=\left(\frac{V_{1}}{V_{0}}\right)^{2} Y_{0} \\
& \text { Number of injured roadusers }(\text { all })=Z_{1}=\left(\frac{V_{1}}{V_{0}}\right)^{2} Y_{0}+ \\
& \left(\frac{V_{1}}{V_{0}}\right)^{4}\left(Z_{0}-Y_{0}\right)
\end{aligned}
$$

Figure 5 - Nilsson's Power Models (R. Elvik, 2010)

Overall, the various studies reviewed Shinar (1998) combined the four conclusions that were typcially consistant throughout the studies. These included:

- Speed is a significant contributing factor to crashes; 
- Specific types of crashes, such as "run-off-the-road" crashes, are definitely associated with high speeds;

- Cars with pre-crash speeds that are either significantly above or below the modal or average travel speed are likely to be overinvolved in crashes; and

- At least part of the over involvement of slow vehicles is due to forced slowing down such as for intersections, avoidance of obstacles, and so forth.

The primary data collection source of this research paper was gathered from Bluetooth detectors installed at select intersections along the arterial roadways. Basic data collection includes two detectors installed on a road, a Bluetooth device's signal is collected and timestamped as it passes each detector. Travel time can then be determined, as the time and distance variables between the two detectors are known. The accuracy of the travel time data produced by the Bluetooth detectors relies heavily on the filtering of data, such as removing duplicates and outliers. "Variability in travel time can arise from a number of well-known sources, such as traffic incidents (vehicle crashes and disablements), work zones, weather, special events, traffic control devices, inadequate base capacity, and traffic demand fluctuations (Federal Highway Administration, 2005)”

Review of urban arterial roadways resulted in significant amount of research pertaining to the purpose and accident prevention. "Urban arterials are an important part of the urban road system. They provide the high-volume network for travel within urban areas. They are also capable of providing access to roadside activities. As a consequence, the management of urban arterials needs to address a wide range of circumstances in the mix of access and movement functions. Management options that are aimed at improving traffic mobility along an arterial have to be weighed against the safety of the arterial.” (Sawalha \& Sayed, 2001) Crash reduction methods and factors have been developed and tested for arterial roadways by various cities, transportation departments and organizations. Given the complexity of urban arterial roadways, crash reduction factors at times have unique applications and vary on a case by case basis.

The information gathered from this literature review, has been implemented in this research project, utilizing both the pre-crash and crash event data to determine comparisons or relationships (if any). 


\subsection{DATA}

\subsection{Speed Data Collection}

Vehicle travel time data collection was implemented by the Portland Bureau of Transportation in collaboration with Metro, Oregon Department of Transportation, Portland State University and various other entities for roadways within the Portland metro area. Portland State University has an archive of the data sets collected by the various entities. The travel time data sets (2010-2015) used in this report were provided from the Portland State University PORTAL data archive, http://portal.its.pdx.edu/ for the Foster road segment between SE $52^{\text {nd }}$ and $82^{\text {nd }}$ Ave.

There are various types of data collection methods in use; however, for this study we used the Bluetooth detectors. An electronic device with Bluetooth functionality emits a signal when enabled. When the electronic device comes into range of the Bluetooth detector (installed along the roadway) the MAC Address of the device is recorded, stored and time-stamped. As the vehicle travels down the roadway segment, additional detector(s) record the identical emitted signal, storing, and time stamping it. The data from the two detectors is cross-referenced, matching any identical MAC addresses and developing travel time for the vehicle between the two points. The travel time is converted into travel speed, using the physical distance between the two detector locations.

\subsection{Crash Data}

The crash data (2010 - 2015) along SE Foster Road between SE 52nd Ave and 82nd Ave was supplied by the Oregon Department of Transportation's Crash Analysis and Reporting Unit. The data was analyzed to determine crash: geographic location, type, severity, and primary cause. Spatial analysis of the crash data is used to identify aggregate locations along the roadway where have crashes occurred shown on Figure 2. Within this time frame there was 411 reported crashes with a total of 892 involved vehicles/bicyclists/pedestrians. Crashes along the roadway segment had a variation of involvement, as there were isolated vehicle crashes as well as crashes where the striking vehicle impacted other vehicle(s), bicycle(s), and/or pedestrian(s). The locations with the highest crash counts include the intersections of SE 52nd Ave, SE 80th Ave, and SE 82nd Ave. 
$52^{\text {nd }}$ and $82^{\text {nd }}$ are four-way controlled vehicular intersections, whereas $80^{\text {th }}$ includes a lighted pedestrian crosswalk with a raised median.

Table 1 - Intersection Crash Count

\begin{tabular}{|c|c|}
\hline $\begin{array}{l}\text { Intersecting Street with SE } \\
\text { Foster }\end{array}$ & $\begin{array}{l}\text { Crash } \\
\text { Count }\end{array}$ \\
\hline Unknown & 27 \\
\hline SE LAFAYETTE ST & 12 \\
\hline SE RHONE ST & 4 \\
\hline SE 51ST AVE & 1 \\
\hline SE 52ND AVE & 57 \\
\hline SE BUSH ST & 2 \\
\hline SE 54TH AVE & 8 \\
\hline SE 56TH AVE & 8 \\
\hline SE GLADSTONE ST & 4 \\
\hline SE 58TH AVE & 8 \\
\hline SE BOISE ST & 1 \\
\hline SE 59TH AVE & 3 \\
\hline SE 60TH AVE & 8 \\
\hline SE CORA ST & 3 \\
\hline SE 61ST AVE & 4 \\
\hline SE 62ND AVE & 9 \\
\hline SE HOLGATE BLVD & 19 \\
\hline SE 63RD AVE & 5 \\
\hline SE 64TH AVE & 7 \\
\hline SE 65TH AVE & 13 \\
\hline SE 66TH AVE & 8 \\
\hline SE 67TH AVE & 16 \\
\hline SE 69TH AVE & 3 \\
\hline SE 70TH AVE & 5 \\
\hline SE 71ST AVE & 2 \\
\hline SE 72ND AVE & 19 \\
\hline SE 73RD AVE & 3 \\
\hline SE 74TH AVE & 12 \\
\hline SE 75TH AVE & 3 \\
\hline SE 76TH AVE & 2 \\
\hline SE 77TH AVE & 6 \\
\hline SE 78TH AVE & 4 \\
\hline SE 79TH AVE & 10 \\
\hline SE 80TH AVE & 29 \\
\hline SE HAROLD ST & 10 \\
\hline SE 82ND AVE & 76 \\
\hline Grand Total & 411 \\
\hline
\end{tabular}


Crash counts are typically uniform throughout the roadway segment, aside from the intersections of larger streets $\left(52^{\text {nd }}\right.$, Holgate, $72^{\text {nd }}$ and $\left.82^{\text {nd }}\right)$. Greater crash count variations are noted at the intersections of $65^{\text {th }}, 67^{\text {th }}$, and $80^{\text {th }}$ avenues. Select intersections with high moderate crash counts and high severity are reviewed in greater depth later in this section, giving and overview, illustration, and general recommendations for improvement.

Review of the crash types show an extremely high rear-end collision count accounting for $48 \%$ of all crashes, followed by a turning movement with $23 \%$ of all crashes. Comparing crash cause Table 3 and type Table 4 we can see a direct relationship with following too closely and a subsequent rear-end collision, followed by failure to yield right-of-way and a turning movement.

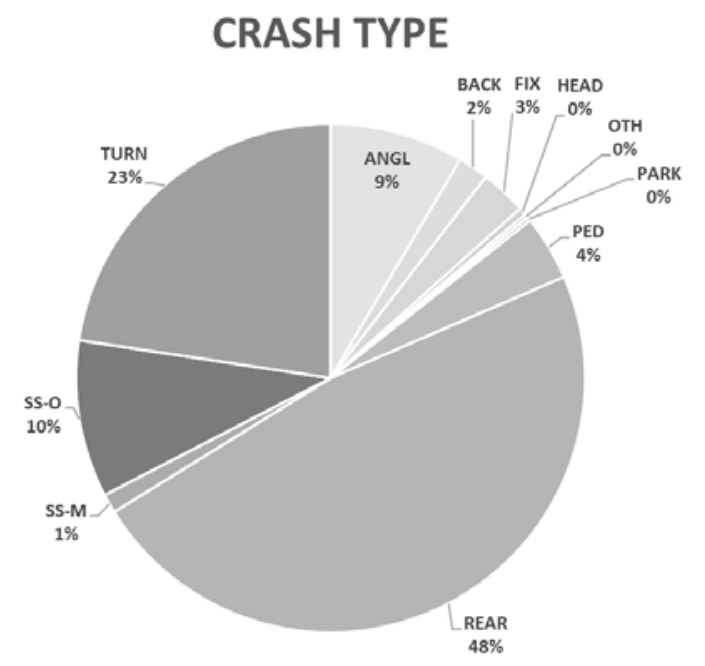

Figure 6 - Crash Type

Table 2 - Crash Type Count

\begin{tabular}{|c|c|l|}
\hline Crash Count Total & $\begin{array}{c}\text { Crash Type Short } \\
\text { Description } \\
\text { ANGL }\end{array}$ & Crash Type Full Description \\
\hline 35 & BACK & Backing \\
8 & FIX & Fixed-Object \\
12 & HEAD & Head-on \\
2 & OTH & Other \\
1 & PARK & Parking Maneuver \\
1 & PED & Pedestrian \\
17 & REAR & Rear-End \\
\hline 196 & SS-M & Sideswipe-Meeting \\
\hline 5 & SS-O & Sideswipe-Overtaking \\
\hline 1 & TURN & Turning Movement \\
\hline 93 &
\end{tabular}


Review of the crash primary crash causes shows an extremely high-count due to "following too closely," and subsequently followed by "did not yield right-of-way.” These two crash causes directly coincide to the primary (rear-end) and secondary (turning) crash types along the roadway segment mentioned previously.

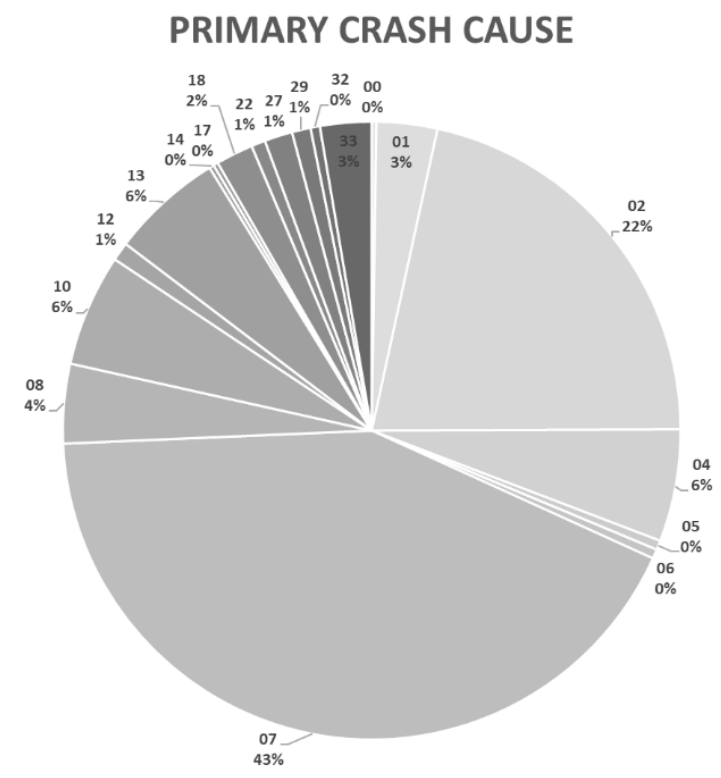

Figure 7 - Primary Crash Cause

Table 3 - Primary Crash Cause Overview

\begin{tabular}{|c|c|l|}
\hline Crash Cause Count & Cause ID & \multicolumn{1}{|c|}{ Primary Crash Cause Detail } \\
\hline 1 & 00 & No Cause Associated At This Level \\
13 & 01 & Speed Too Fast For Conditions \\
88 & 02 & Did Not Yield Right-Of-Way \\
24 & 04 & Disregarded R-A-G Traffic Signal. \\
2 & 05 & Drove Left Of Center On Two-Way Road \\
2 & 06 & Improper Overtaking \\
174 & 07 & Followed Too Closely \\
17 & 08 & Made Improper Turn \\
24 & 10 & Other Improper Driving \\
4 & 12 & Other (Not Improper Driving) \\
24 & 13 & Improper Change Of Traffic Lanes \\
1 & 14 & Disregarded other traffic control device \\
1 & 17 & Physical Illness \\
8 & 18 & Non-Motorist illegally in roadway \\
3 & 22 & Inadequate or no brakes \\
6 & 27 & Inattention \\
4 & 29 & Failed To Avoid Vehicle Ahead \\
2 & 32 & Careless Driving (Per Par Or Self-Reported) \\
11 & 33 & Reckless Driving (Per Par Or Self-Reported) \\
\hline
\end{tabular}


Within the five-year time frame (2010-2015), two fatalities occurred along the roadway section, both with pedestrian casualties. In addition, there were 10 severe injuries (type A), 57 moderate injuries (type B) and 227 minor or possible injuries (type C). Of the 10 type A injuries a striking motorized vehicle was involved with a pedestrians 3 times and with bicycles two times. Of the 57 type B injuries, a striking motorized vehicle was involved with pedestrians thirteen times and with bicycles nine times. 17 of the 17 (100\%) total crashes involving a pedestrian resulted in a fatality, type A, or B injury. 11 of the 16 (69\%) total crashes involving a bicycle resulted in a type A or B injury.

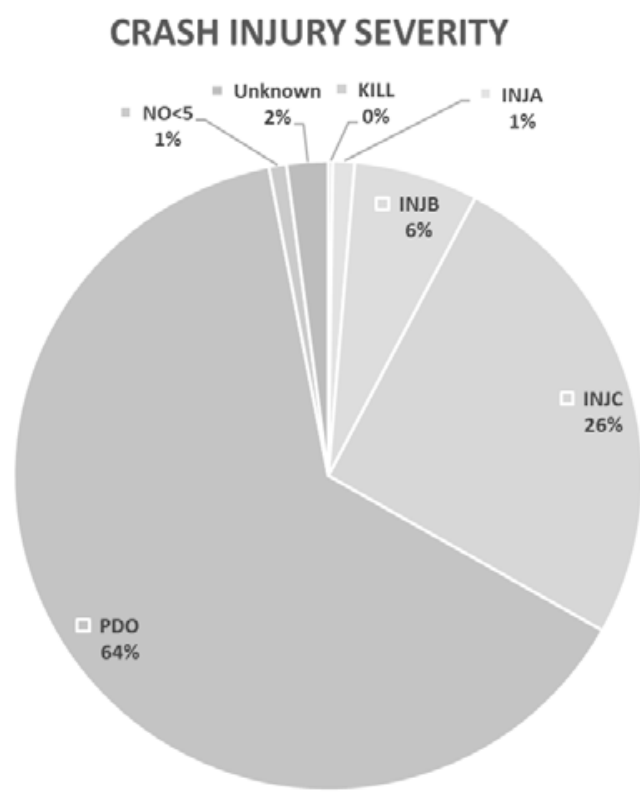

Figure 8 - Crash Injury Severity

Table 4 - Crash Injury Severity Count and Description

\begin{tabular}{|c|c|c|c|l|}
\hline $\begin{array}{c}\text { Striking } \\
\text { Vehicle }\end{array}$ & Casualties & Total & $\begin{array}{c}\text { Short } \\
\text { Description }\end{array}$ & \multicolumn{1}{|c|}{ Long Description } \\
\hline 0 & 2 & 2 & KILL & Fatality \\
\hline 2 & 8 & 10 & INJA & Incapacitating Injury - Bleeding, Broken Bones \\
\hline 24 & 33 & 57 & INJB & Non-incapacitating Injury \\
\hline 47 & 180 & 227 & INJC & Possible Injury \\
\hline 332 & 237 & 569 & PDO & Property Damage Only \\
\hline 4 & 4 & 8 & NO $<5$ & No Injury - 0-4 Years of Age \\
\hline 19 & 0 & 19 & Unknown & Unknown \\
\hline & Total & 892 & & \\
\hline
\end{tabular}




\subsection{Data Statistical Characterization and Analysis}

The speed data collected (mph) was averaged into a one hour windows, per 24-hour period for each day of the week. Additionally, a standard deviation of the mean speed was generated to develop the amount of variation is travel speed. Average travel speeds for the length of the roadway varied slightly by time of day, ranging from 25 mph during non-peak and 18-20 mph during peak times. The speed limit for the roadway segment is 35 miles per hour (mph), meaning the collected data of vehicle speeds are influenced by traffic control devices and volume. We can assume the non-peak travel time of $\sim 25 \mathrm{mph}$, the vehicles speed after acceleration/decelerations from traffic control devices would be around or slightly greater than $35 \mathrm{mph}$. Expanding that assumption, during peak times the average speed would fall around 24-26 mph.

The highest involvement rate occurs during peak travel times, including higher volumes of traffic and lower average speeds are maintained. The most common crash type is a rear-end supported with the primary crash causation of following too close. The high quantity of rear end crashes reported in the roadway segment where removed to determine if additional relationships or observations are present, as rear-end crashes are commonly associated with high volume and/or congestion. With the rear-end crashes removed travel speed data was compared to the vehicle crash count in Figure 9, illustrating the relationship between the crash count and average speed during the time of day.

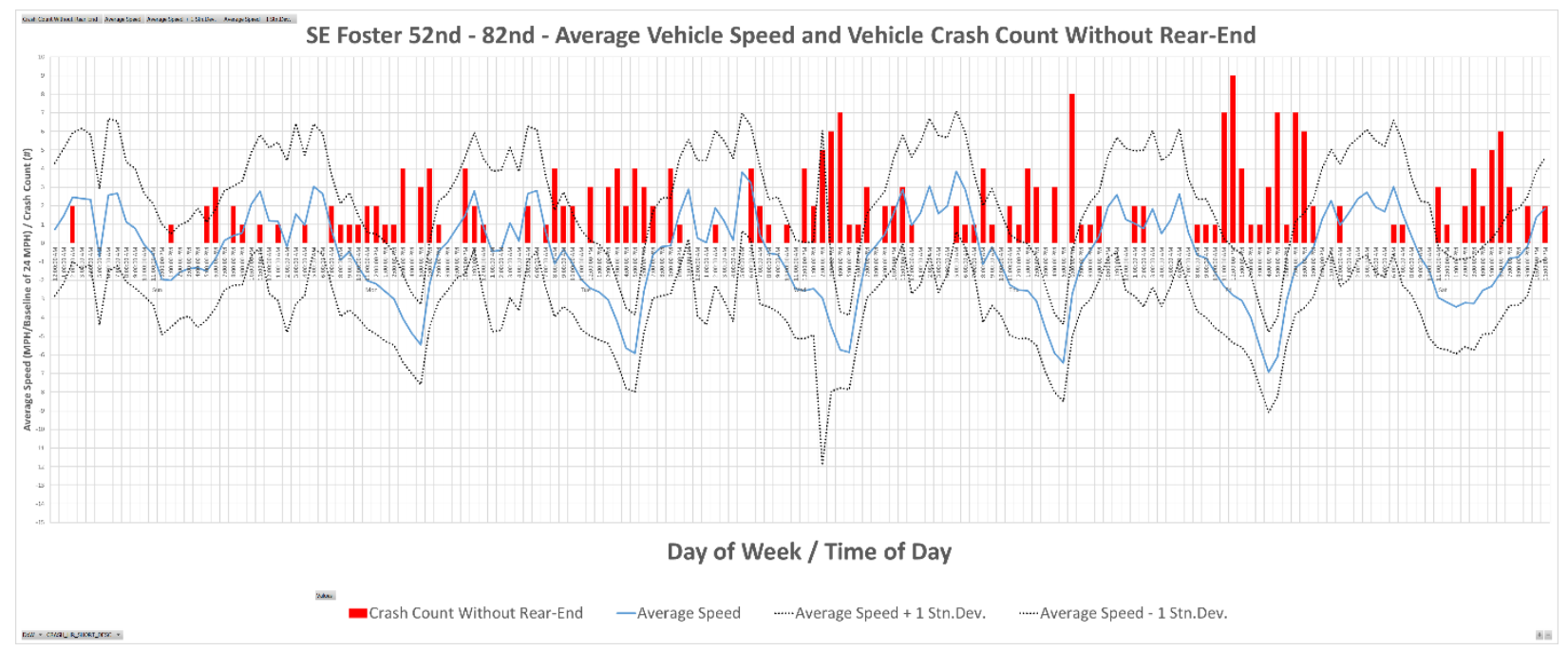

Figure 9 - Time of Day/Week vs. Average Vehicle Speed and Crash Count without Rear End 
Assessing the data provided in both the crash and speed sections as depicted in Figure 9, these main observations are developed:

1. The probability of being in a crash during free-flow travel times / off-peak hours is significantly less. This is also the time of day where the highest average speeds are achieved.

2. With the removal of rear-end crashes, the crash occurrences beings to normalize throughout the daytime with the variations in average speed. Extremes still occur during peak travel times on Wednesday, Thursday, and Friday afternoons.

The crash counts were plotted against the deviation from mean speed (Figure 10), illustrating significantly higher crash counts at speeds below the mean speed. This signifies a similar trend of "variation from the mean traffic speed results in higher crash involvement rates" (Solomon, 1964). Crashes that occur at lower speeds correlate to volume along the roadway, higher number of vehicles directly correlates to higher probability of crash involvement rates.

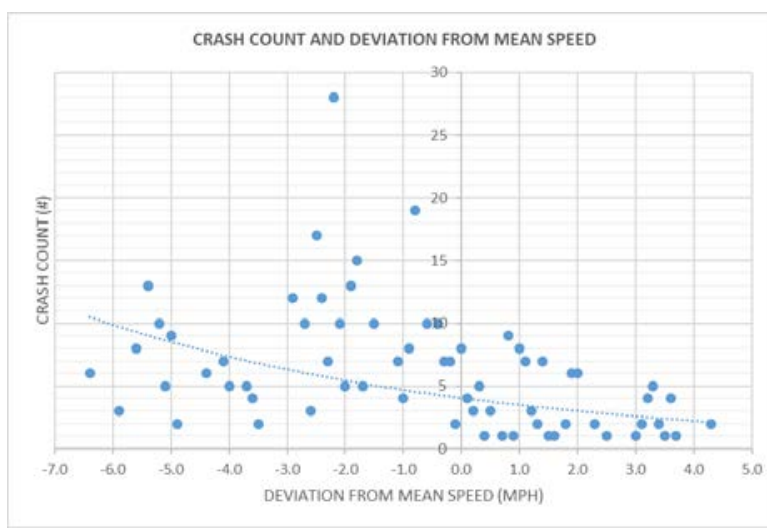

Figure 10 - Crash Count at Deviation from Mean Speed

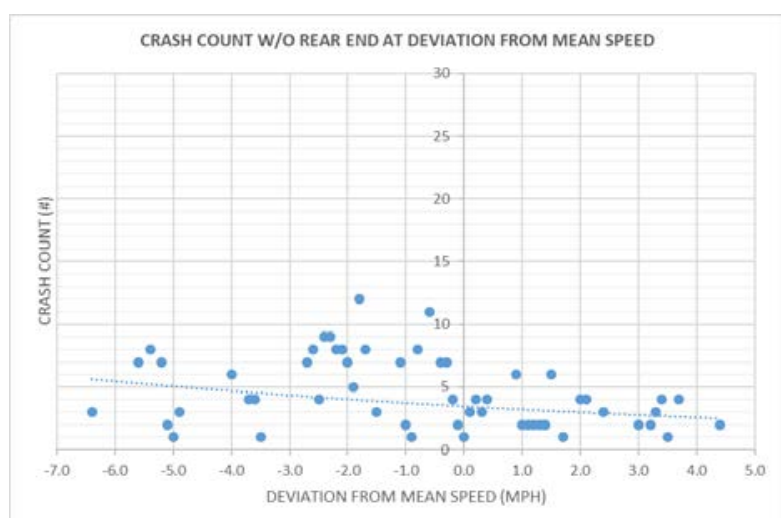

Figure 11 - Crash Count without Rear End at Deviation from Mean Speed

Rear-end crashes were removed from the graph Figure 11, illustrating the crash count of all other combined crash types at deviations from the mean speed in Figure 12. The tail end of the trendline in the lower speed deviations drops significantly, confirming that a majority of the rearend crashes are primarily related to traffic volume placing speed in a lower tier of the contributing 
causation factors. Additional graphs illustrating the unique crash type were developed and are illustrated in Figures 13 through 19.

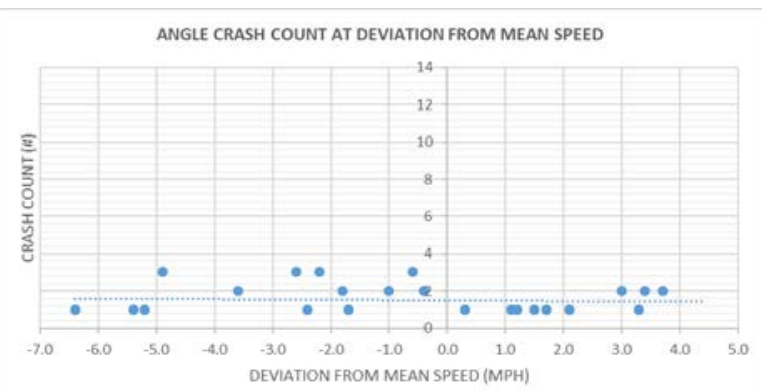

Figure 12 - Angle Crash Count at Deviation from Mean Speed

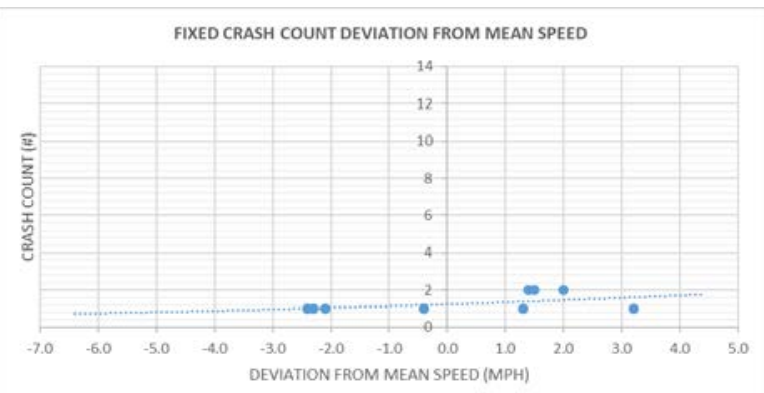

Figure 14 - Fixed Crash Count at Deviation from Mean Speed

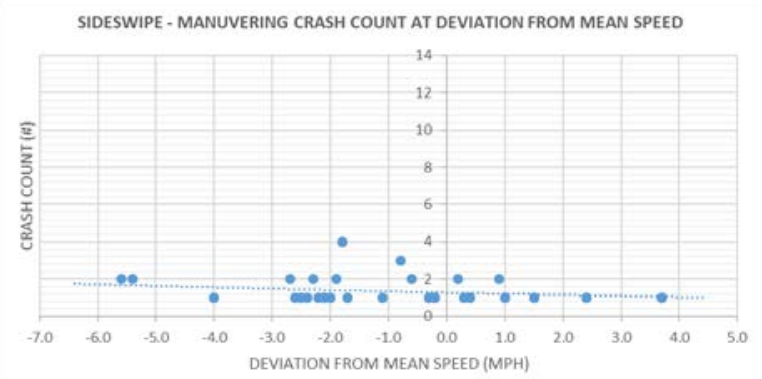

Figure 16 - Sideswipe Crash Count at Deviation from Mean Speed

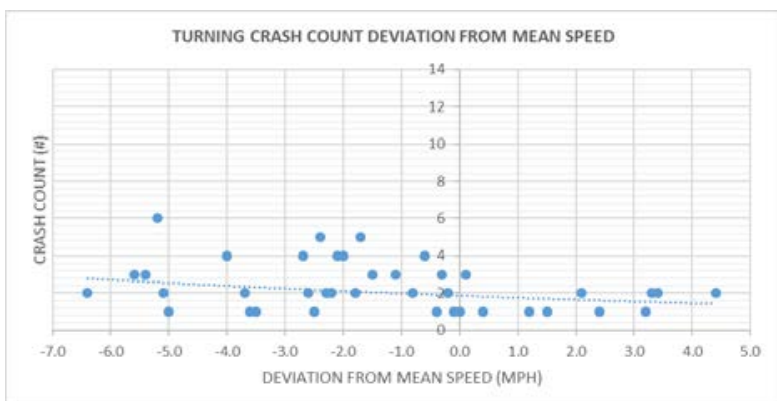

Figure 18 - Turning Crash Count at Deviation from Mean Speed

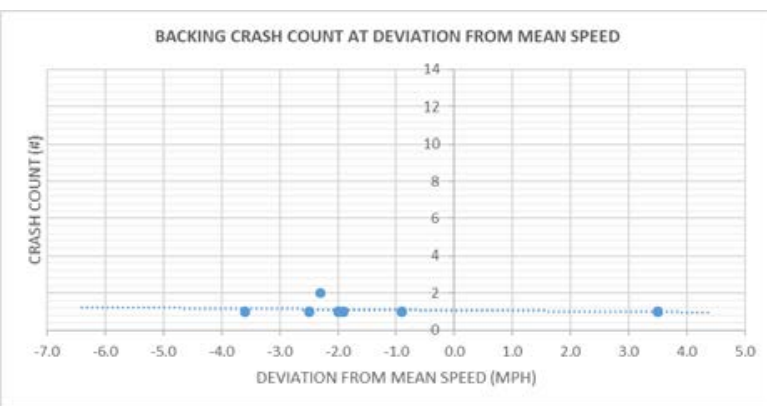

Figure 13 - Backing Maneuver Crash Count at Deviation from Mean Speed

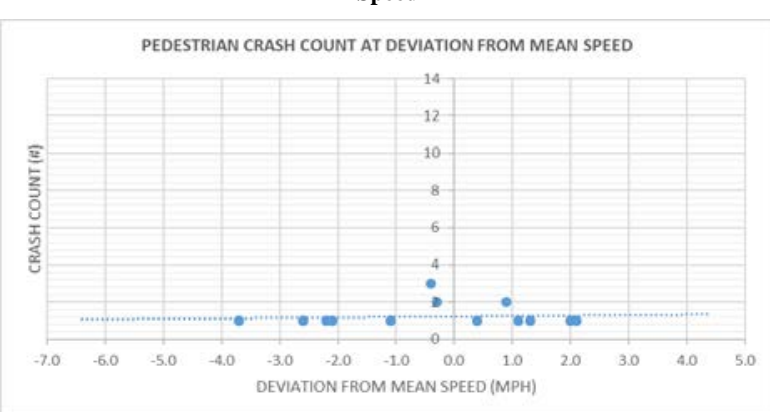

Figure 15 - Pedestrian Crash Count at Deviation from Mean Speed

SIDESWIPE - OVERTAKING CRASH COUNT AT DEVIATION FROM MEAN SPEED

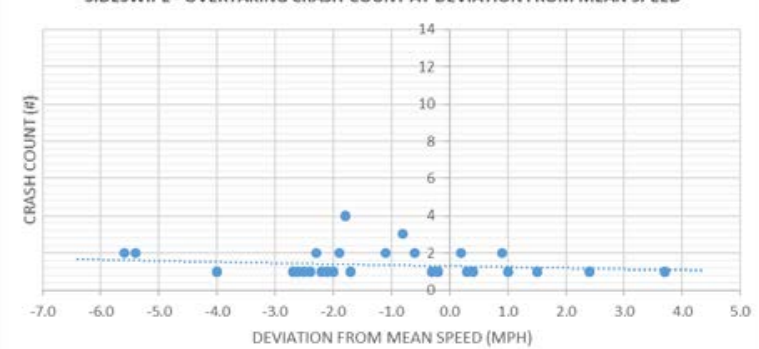

Figure 17 - Overtaking Crash Count at Deviation from Mean Speed 
Three main groups can be observed from the various types of crashes that occur along the SE Foster roadway segment: (1) Angle, backing maneuver, and pedestrian crashes have a nearly horizontal linear trendline, with moderate crash dispersion both above and below the mean speed. (2) Sideswipe, overtaking, and turning crashes are heavily concentrated at speeds lower than average. (3) Fixed crashes mostly occur at speeds above the average, although there is a low occurrence rate.

Correlation function was used to develop a measure the degree between the average vehicle speed and crash count during the time of day/week. A correlation coefficient is determined, ranging between +1.0 (positively correlated) and -1.0 (negatively correlated). A return value near zero indicates that no correlation exists or was determined. The correlation of a population is expressed by:

$$
\rho(x, y)=\frac{\operatorname{Cov}(x, y)}{\sigma_{x} \sigma_{y}}
$$

Where $\operatorname{Cov}$ is the covariance of the pair (x,y), $\sigma_{x}$ is the standard deviation of $\mathrm{x}$ and $\sigma_{y}$ is the standard deviation of $y$. Correlations between the average speed and crash count type are shown in Table 5, where a strong positive correlation is identified by $\rho \geq 0.40$, moderate correlation is in the range of $0.20<\rho<0.40$, and weak or negligible correlations have $\rho \leq 0.20$. Negative correlations would be the inverse from positive correlation, strong $(\rho \leq-0.40)$, moderate $(-0.20>$ $\rho>-0.40)$ and weak $(\rho \geq-0.20)$.

Table 5 - Correlation between Average Speed and Crash Count by Type

\begin{tabular}{|l|c|c|}
\hline & \multicolumn{2}{|c|}{ Average Speed } \\
\hline & Correlation Coeff. $(\rho)$ & P-Value \\
\hline Crash Count - All & -0.58 & $1.2 \mathrm{E}-16$ \\
Crash Count w/o Rear & -0.35 & $3.3 \mathrm{E}-09$ \\
\hline Crash Count - Rear-End & -0.48 & $3.1 \mathrm{E}-11$ \\
Crash Count - Angle & -0.04 & 0.052 \\
Crash Count - Backing & -0.17 & 0.11 \\
Crash Count - Fixed & 0.37 & 0.44 \\
Crash Count - Head-On & - & 0.58 \\
Crash Count - Other & - & 0.12 \\
Crash Count - Pedestrian & 0.08 & 0.67 \\
Crash Count - Sideswipe - Maneuvering & -0.15 & $4.8 \mathrm{E}-04$ \\
Crash Count - Turning & -0.36 & $2.9 \mathrm{E}-10$ \\
Crash Count - Sideswipe - Overtaking & -0.15 & $9.3 \mathrm{E}-04$ \\
\hline
\end{tabular}


The second column designates the significance factor $(\mathrm{P})$, determined from the regression analysis. A value less than .05 (alpha =.05) means the aligning correlation value is statistically significant. Values greater than .05 denote that there is a $5 \%$ weak or little evidence the correlation data is reliable. This occurs with the crash count types with limited occurrences, there is not sufficient data to determine a P-value with strong evidence. More years of crash and speed data would need to be added into the analysis to determine if there is stronger evidence against the null hypothesis (speed and crash correlations).

Majority of the correlations developed in Table 5 have negative coefficients, indicating a relationship with lower deviations from the mean speed. Rear-end crashes have a strong correlation with lower speeds, along with a moderate negative correlation for turning movements. Fixed crash

types have a moderate positive correlation with average speeds above the mean. This would conclude that higher speed above the mean, or free-flow of traffic times result in higher fixed object crash occurrences.

\subsection{Crash Forecasting with Speed Variation Models}

The majority of crashes occur during both morning and afternoon commutes, peak travel time and the highest vehicle miles traveled (VMT) period for the roadway. Assuming roadway conditions remain the same, we can use speed and road crash relationships previously developed by Nilsson (1981) using six different power functions to project crashes and casualties along the corridor. "Nilsson's relationships were empirically derived based on speed changes and crash effects resulting from a large number of rural speed limit changes” in Sweden, determining increase crash severity coincided with an increase in speed. These power functions were subsequently modified by Elvik (2009) using a meta-analysis to apply to urban arterial roadways, changing the exponential in the power function slightly. The power functions were applied to the Foster roadway to assuming both a $5 \mathrm{mph}$ decrease and $5 \mathrm{mph}$ increase. 
Table 6 - Power Functions - 5 mph Increase

\begin{tabular}{|c|c|c|c|c|c|}
\hline \multicolumn{6}{|c|}{5 MPH INCREASE } \\
\hline & $\begin{array}{l}2010- \\
2015\end{array}$ & Power & $\begin{array}{l}\text { Projected } \\
\text { (5 Year total) }\end{array}$ & $\begin{array}{l}\text { Change }(\Delta) \\
\text { (5 Year total) }\end{array}$ & $\begin{array}{c}\% \\
\text { Increase }\end{array}$ \\
\hline \multicolumn{6}{|l|}{ Crashes* } \\
\hline Fatal Crashes & 2 & 2.6 & 3 & 1 & $49 \%$ \\
\hline Serious Injury (A\&B) & 67 & 1.5 & 84 & 17 & $26 \%$ \\
\hline Slight Injury (C) & 227 & 1 & 265 & 38 & $17 \%$ \\
\hline Property Damage Only & 569 & 0.8 & 644 & 75 & $13 \%$ \\
\hline \multicolumn{6}{|l|}{ Casualties } \\
\hline Fatalities & 2 & 3 & 3 & 1 & $59 \%$ \\
\hline Seriously Injured & 33 & 2 & 45 & 12 & $36 \%$ \\
\hline Slight Injured & 180 & 1.1 & 213 & 33 & $18 \%$ \\
\hline
\end{tabular}

*Crashes includes all vehicles, bicyclists, or pedestrians involved in a single crash event

Table 7 - Power Functions - 5 mph Decrease

\begin{tabular}{|c|c|c|c|c|c|}
\hline & $2010-2015$ & Power & $\begin{array}{c}\text { Projected } \\
(5 \text { Year total) }\end{array}$ & $\begin{array}{c}\text { Change }(\Delta) \\
(5 \text { Year total) }\end{array}$ & $\begin{array}{c}\% \\
\text { Increase }\end{array}$ \\
\hline Crashes* & & & & & \\
\hline Fatal Crashes & 2 & 2.6 & 1 & -1 & $-38 \%$ \\
\hline Serious Injury (A\&B) & 67 & 1.5 & 51 & -16 & $-24 \%$ \\
\hline Slight Injury (C) & 227 & 1 & 189 & -38 & $-17 \%$ \\
\hline Property Damage Only & 569 & 0.8 & 492 & -77 & $-14 \%$ \\
\hline Casualties & & & & & \\
\hline Fatalities & 2 & 3 & 1 & -1 & $-42 \%$ \\
\hline Seriously Injured & 33 & 2 & 23 & -10 & $-31 \%$ \\
\hline Slight Injured & 180 & 1.1 & 147 & -33 & $-18 \%$ \\
\hline
\end{tabular}

Projecting out five years, and with a $5 \mathrm{mph}$ decrease of the Foster roadway, we would see a significant reduction of roughly 132 crashes including a reduction in both fatal (-38\%) and series injury (-24\%) crashes. Whereas $5 \mathrm{mph}$ increase, to $40 \mathrm{mph}$ would potentially lead to an increase of additional 131 crashes with an increase in both fatal (49\%) and series injury (26\%) crashes. Top crash types for the years of 2010-2015 being rear-end at $42 \%$ and the crash cause of "followed too closely" at 37\%, we can assert that drive distraction or inattention with limited response time during high volume travel times is the primary cause of crashes. 


\subsection{SE Foster Roadway Improvement Plan}

The City of Portland has released a "Foster Road Transportation and Streetscape Plan” dated May 2014, which is currently proposed to be physically implemented and constructed during 2017 through 2018. The work includes a reduction in the number of lanes from four to three, including one lane each way with a refuge/turning center lane. Bike lanes will be added on both sides, along with widening of the sidewalks. The plan is essentially a "road diet," a term described a reduction in the vehicle lanes along a roadway, reallocating space for other modes of traveling. Single lanes cannot accommodate the same volume miles travels as double lanes, so it relies on heavily on traffic diversion. Diversion of traffic would include an increase of vehicle miles traveled along SE Holgate Boulevard, Powell Boulevard, SE 82 ${ }^{\text {nd }}$ and SE 52 ${ }^{\text {nd }}$ Avenues. (City of Portland, Bureau of Transportation, 2014)

As mentioned previously, the intersections of SE 52nd Ave, SE 80th Ave, and SE 82nd Ave have the highest crash counts in respect to other locations along the roadway. Continuing with the omission of rear-end crashes, high severity crashes were determined by the location and type of collision type.

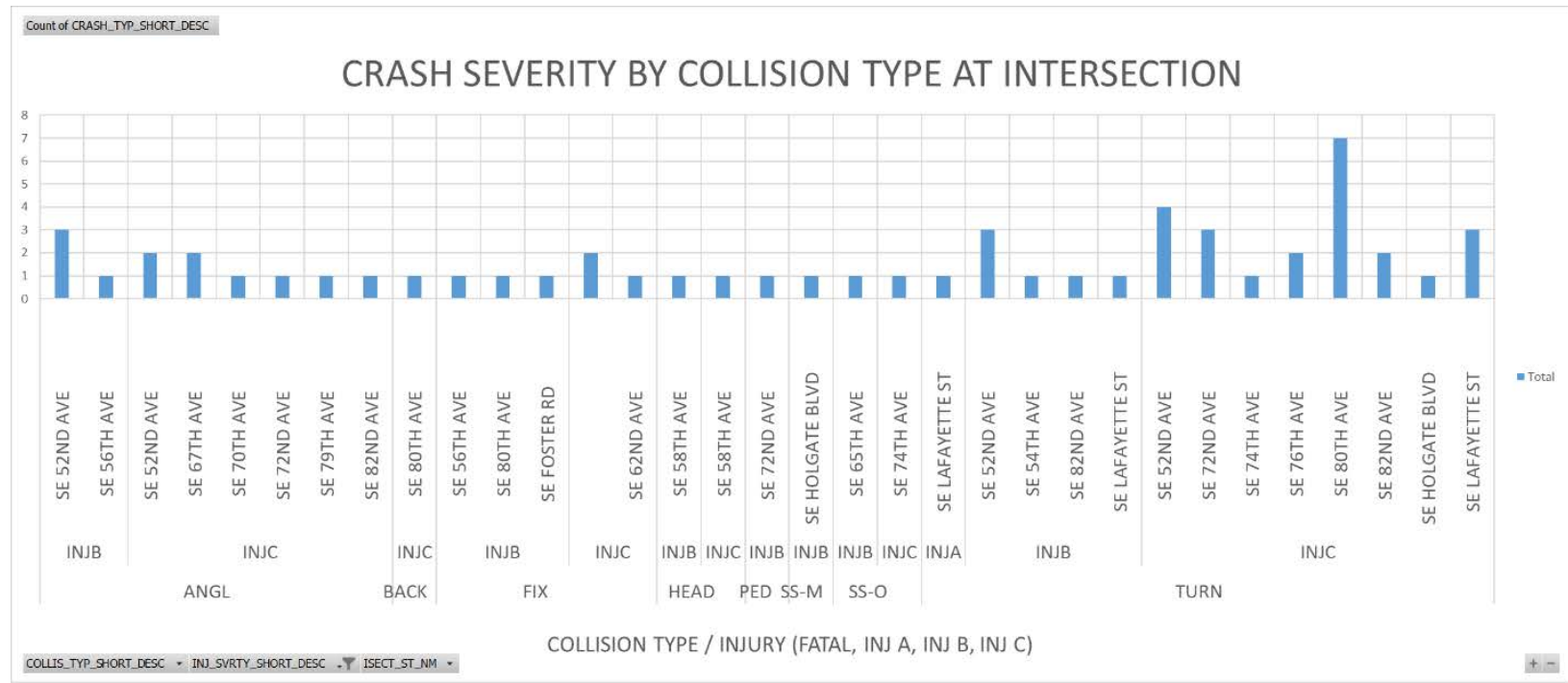

Figure 19 - Crash Severity by Collision Type at Intersection with SE Foster 
Angle and turning movements at the intersections of SE $52^{\text {nd }}, 72^{\text {nd }}$, and $80^{\text {th }}$ avenues have the highest for crashes with high severity. The following section provides an illustrative representation to the high severity crash types, and the physical maneuvers of vehicles.

\subsubsection{SE 52 ${ }^{\text {nd }}$ Ave and SE Foster Rd Intersection Analysis}

Southeast $52^{\text {nd }}$ avenue includes 3 lanes, with a center lane running North and South which intersects the 4-5 lane Foster road orientated Northwest and Southeast shown in Figure 22 (below). Review of the vehicle maneuvers that resulted in a severe injury, shows most of the crashes are a result of disregarding a R-A-G traffic signal. Vehicles making left turns from SE $52^{\text {nd }}$ heading South to Northwest are impacted by a vehicle heading Northwest to Southeast on SE Foster road and the mirror image of left turns from SE $52^{\text {nd }}$ heading North to Southeast, impacted by a vehicle heading Southeast to Northwest on SE Foster road are the primary crash types at this intersection. If the left-hand turn signal is not triggered, the same pattern is occurring to vehicles heading North and South on SE $52^{\text {nd }}$ Ave, impacted by a vehicle on SE Foster road disregarding the R-A-G traffic signal. 


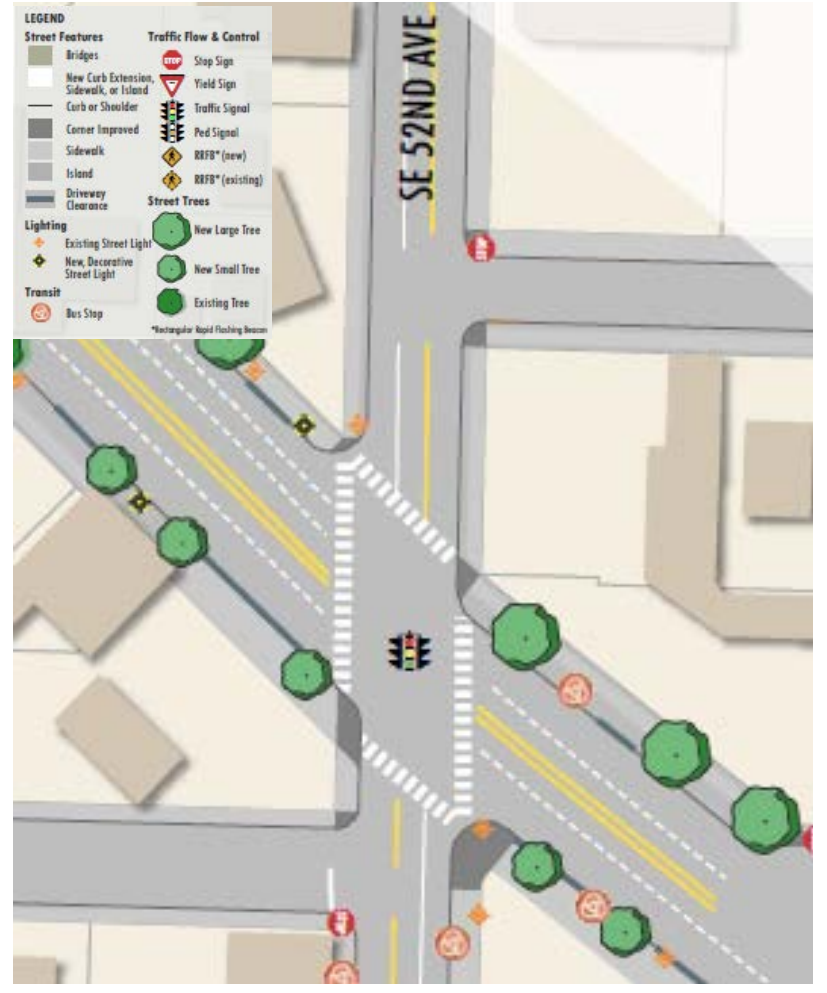

Figure 20 - SE $52^{\text {nd }}$ Ave and SE Foster Rd Planned Intersection Improvements

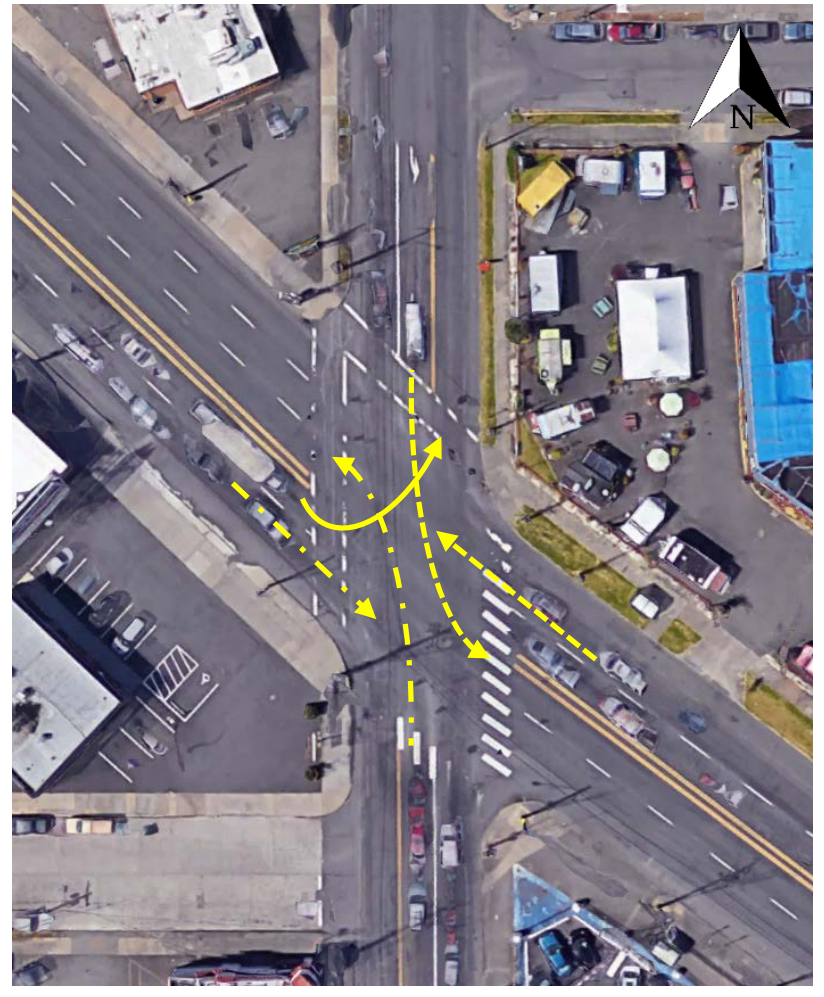

Figure 21 - Aerial Photograph of SE 52 ${ }^{\text {nd }}$ Ave and SE Foster Rd Intersection

Additionally, vehicles making left turns from SE Foster Road heading Northwest to North on SE $52^{\text {nd }}$ Ave occur even though current striping does not permit this maneuver.

Currently there is no plan to change to the lane configuration for either roadway, just minor sidewalk extensions. Possible low-cost countermeasures include reevaluation of the signal timing, primarily amber phase for vehicles traveling on SE Foster Road, as well as possible increase of the timing between the start of the red-light phase on SE Foster road and the activation of the green turn signal for SE $52^{\text {nd }}$ Ave. This would allow vehicles that disregard the traffic signal additional time to get through the intersection before vehicles from SE $52^{\text {nd }}$ Ave entered. Additionally, signage for no left-hand turn should be posted from span wires with the traffic signals, and street signage indicated only straight or right-hand turn maneuvers for vehicles traveling on SE Foster Rd through the intersection. 


\subsubsection{SE 72 ${ }^{\text {nd }}$ Ave and SE Foster Rd Intersection Analysis}

Southeast $72^{\text {nd }}$ avenue includes 3 lanes, with a center lane at the South and a raised median at the North where it intersections SE Foster Rd. SE Foster Rd. has 5 lanes, two lanes of travel each direction with a center turn lane orientated Northwest and Southeast. An overview of the intersection is shown in Figure 24 along with the proposed improvements Figure 23 (below).

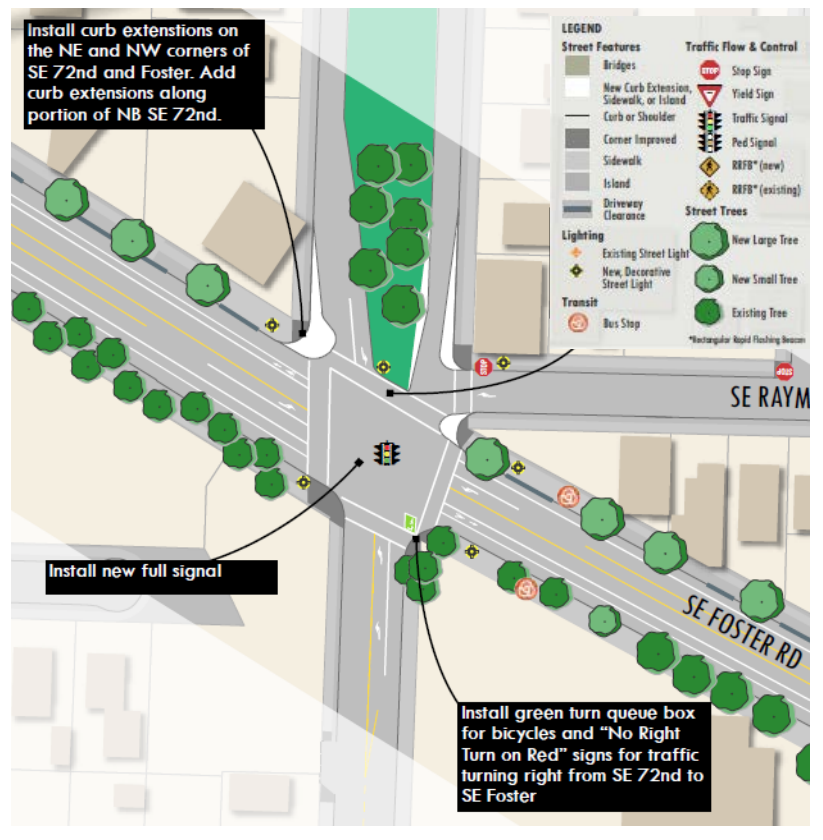

Figure 22 - SE $72^{\text {nd }}$ Ave and SE Foster Rd Planned Intersection Improvements

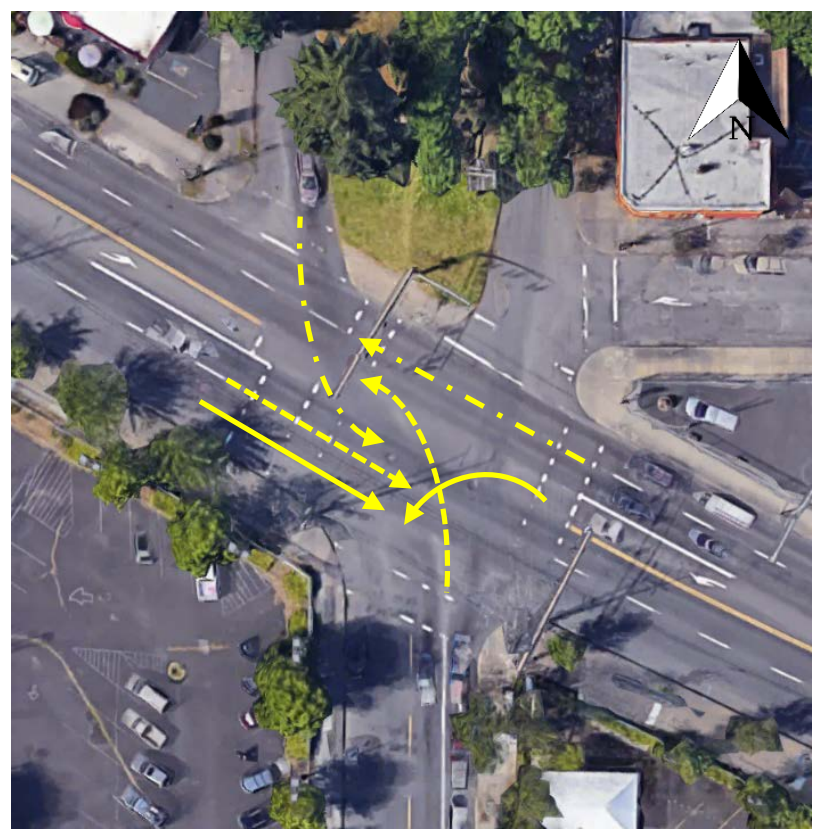

Figure 23 - Aerial Photograph of SE $72^{\text {nd }}$ Ave and SE Foster Rd Intersection

The following primary crashes resulting in injury are illustrated on Figure 24:

- Left-turn from SE Foster Rd heading NW onto SE $72^{\text {nd }}$ Ave heading South (solid lines)

- Left turn from SE $72^{\text {nd }}$ Ave North heading to SE Foster Rd heading Southeast (dashed line with dot)

- Left turn from SE $72^{\text {nd }}$ Ave South heading to SE Foster Rd heading Northwest (dashed line)

The left turn movements from vehicles on SE $72^{\text {nd }}$ going onto SE Foster road have identical crashes causes as noted in the previous intersection (3.5.1) which are a result of vehicles traveling on SE 
Foster road disregarding the R-A-G traffic signal and "running the red light.” Other crashes are vehicles turning left from SE Foster Rd onto SE $72^{\text {nd }}$ Ave, failing to yield to on-coming traffic. Vehicle speed may be a contributing factor to these types of crashes, as the approaching vehicle may be exceeding the posted speed, reducing the time for the vehicle making to the left hand turn to clear the intersection.

Countermeasures for this intersection include modification to the signal timing to increase of the timing between the start of the red-light phase on SE Foster road and the activation of the green turn signal for SE $72^{\text {nd }}$ Ave. The reduction down from two to one on-coming lane will prevent vehicles "hidden" in the outside lane during turning maneuvers.

\subsubsection{SE 80 ${ }^{\text {th }}$ Ave and SE Foster Rd Intersection Analysis}

The intersection of $80^{\text {th }}$ and SE Foster Road Figure 12 is uncontrolled, with no center refuge lane for a turning movement. Additionally, a controlled pedestrian crosswalk is installed adjacent to the intersection with a raised median. The highest similar crashes involved rear-end collision (15), with two vehicles traveling in the same directing, with one stopping. The second highest cause included a turning movement with the vehicle entering the road at an angle, all of which occurs between 3:00 and 4:00 PM. The rear-end crashes are most likely attributed to the signalized pedestrian cross-walk, given long roadway stretch without a controlled intersection when heading SE. The proposed reduction of lanes for this section from four to three as shown in Figure 25, will reduce rear end collisions by removing stopped turning vehicles from the through lane, as well as providing a refuge lane for vehicles turning left from SE $80^{\text {th }}$ Ave onto SE Foster Rd. heading Southeast. 


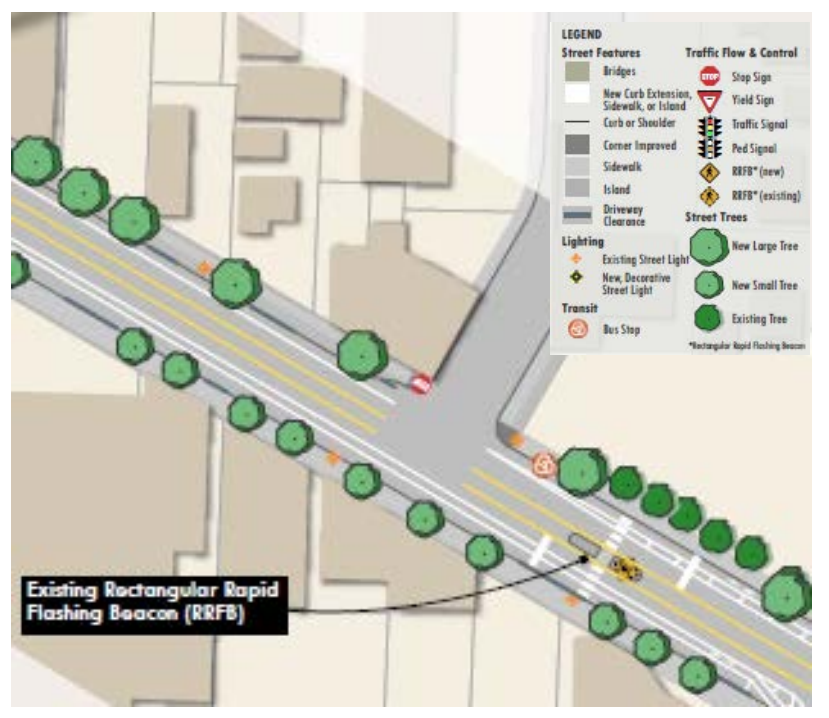

Figure 24 - SE 80 ${ }^{\text {th }}$ Ave and SE Foster Rd Planned Intersection Improvements

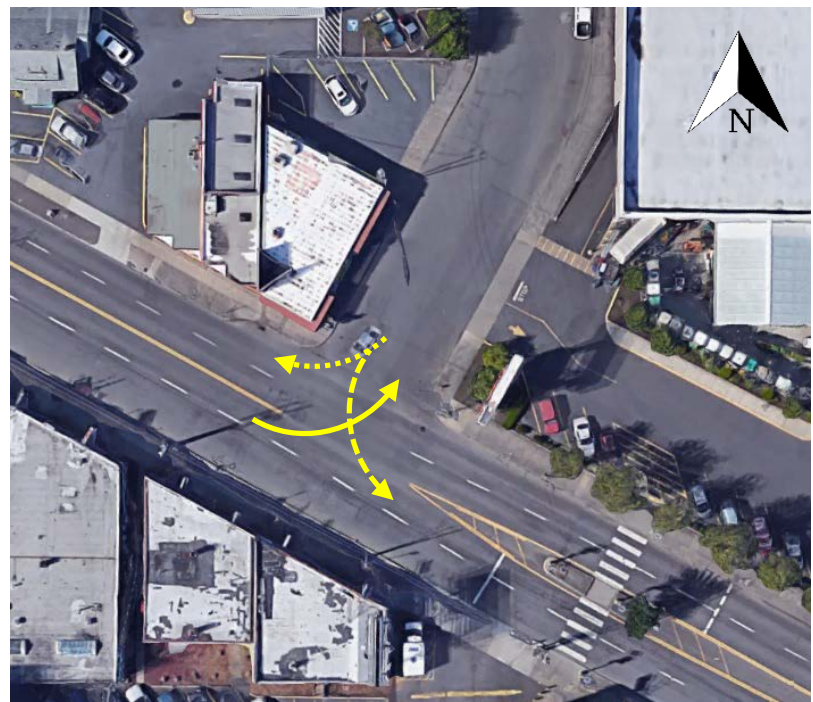

Figure 25 - Aerial Photograph of SE $\mathbf{8 0}^{\text {th }}$ Ave and SE Foster Rd Intersection

The following turning crashes resulting in injury are illustrated on Figure 26:

- Right turn from SE $80^{\text {th }}$ Ave to SE Foster Rd heading Northwest -4 Crashes

- Left-turn from SE Foster Rd to SE $80^{\text {th }}$ Ave -7 Crashes

- Left turn from SE $80^{\text {th }}$ Ave to SE Foster Rd heading Southeast -3 Crashes

The limited sight distance for vehicles turning onto Foster, along with lighted pedestrian crossing are influencing the higher crash rate at this location. A signalized pedestrian crossing, instead of the immediate flashing yellow lights, would notify vehicles to slow-down earlier and not abrupt stops when the signal is engaged.

Overall the three intersections depicted in this section vary due to the physical configuration. Vehicle speeds of the impacting vehicles are likely a contributing factor; however, the speed data provided does not provide sufficient detail to determine a relationship between the turning vehicles and the impacting typically traveling straight. 


\subsection{CONCLUSIONS}

The SE Foster roadway between has been identified by Portland Bureau of Transportation as a "high crash corridor" in 2011; however, a large amount of the reported crashes occurs outside of the SE Foster roadway segment reviewed in this research paper. Vehicle speeds along the corridor do not appear to deviate substantially from the designated speed limit during free flow traffic. Crashes have a greater occurrence rate during a reduction in average vehicle speeds. The reduction in vehicle speeds typically occurs during peak times is a result of high volume and static roadway characteristics. Rear-end crashes accounted for $48 \%$ of the total crashes were determined to have a -.48-correlation value to average vehicle speed, establishing that rear-end crashes occur more frequently during lower average speeds. During congestion, two lanes of traffic traveling in each direction will have varying speeds at times, and we can revert to the statement within the literature review section stating: "two-car following situation, slowing vehicles are more likely to be struck than fast vehicles because when they slow down, drivers behind them are often not immediately aware of the speed change, and thus slowing down reduces the headways of cars behind them. This may create imminent crash situations because of lapses in attention of following drivers, slowed responses of the following drivers, or misperception of the reduced gap by the following drivers.” (Shinar, 1998)

Striking vehicles involved in angle and turning maneuvers crash types may be correlated to high speeds along the roadway segment; however, the speed data provided is insufficient to determine vehicle approach speeds into and/or exiting the intersections. Driver disregard for the R-A-G traffic signals while approaching an intersection is identified as a primary cause to these types of crashes. Vehicles do not typically reduce speed, but rather increase speed to make it through an intersection prior to a red light during the amber phase.

The variable of vehicle speed on the SE Foster corridor has an influence on the safety of the roadway; however, excessive vehicle speeds do not appear to be top tier cause of crashes. The roadway characteristics in combination with high traffic volumes and driver inattention are the primary influence on the crashes occurring. Previously mentioned roadway characteristics refers to the traffic/pedestrian controls and the physical angle of SE Foster with the non-perpendicular intersections for streets running North/South and/or East/West. A reduction in the speed limit 
and/or redesign of the roadway (intersections and increased visibility prior to turns) would provide a substantial decrease in crashes. Upon completion of the Foster Road Transportation and Streetscape Plan by the City of Portland, the speed and crash data can be compared to the preexisting conditions to determine impact the reduction of crashes and injuries sustained by crashes (if any). 


\subsection{REFERENCES}

B.N. Fildes, G. R. (1991). SPEED BEHAVIOUR AND DRIVERS' ATTITUDE TO SPEEDING. Melbourne, Australia : Monash University Accident Research Center.

Bullock, R. H. (2011). Probe Vehicle Re-Identification Data Accuracy Evaluation. West Lafayette, IN: Purdue University.

Chengcheng Xua, A. P. (2013). Predicting Crash Likelihood And Severity On Freeways With Real-Time. Accident Analysis And Prevention, 30-39.

Chris Lee, B. H. (2006). Evaluation Of Variable Speed Limits To Improve Traffic Safety. Transportation Research Part C: Emerging Technologies, 213-228.

City Of Portland, Bureau Of Transportation. (2014). Foster Road Transportation And Streetscape Plan. Portland, Oregon.

Gattis, E. D. (2017). Safe Streets, Livable Streets. Journal Of The American Planning Association, 283-300.

Haddon, W. (1980). Options For The Prevention Of Motor Vehicle Crash Injury. Jerusalem, Israel: Israel Journal Of Medical Sciences.

Hauer, E. (2014). Speed And Safety. Transportation Research Record: Journal Of The Transportation Research Board, 10-17.

Li Jie, H. V. (2011). Monitoring Travel Times In An Urban Network Using Video, GPS And Bluetooth. Procedia Social And Behavioral Sciences.

Mclean, M. N. (2012). BRINGING YOU UP TO SPEED: Health And Economic Model Of The Effects Of Raising The Speed Limit On New Zealand State Highways And Motorways From $100 \mathrm{~km} / \mathrm{H}$ To $110 \mathrm{~km} / \mathrm{H}$. Otago, Wellington: University Of Otago.

Metro. (2012). Metro State Of Safety Report: A Compilation Of Information On Roadway-Related Crashes, Injuries, And Fatalities. Portland. 
Mike Mauch (DKS Associates). (2013). Analysis Procedures Manual User Group (APMUG); Data Mining INRIX Traffic Speed Data.

Mohamed Abdel-Aty, A. P. (2005). Identifying Crash Propensity Using Specific Traffic Speed Conditions. Journal Of Safety Research, 97-108.

Nicholas J. Garber, R. G. (1988). Speed Variance And Its Influence On Accidents. Charlottesville, VA: University Of Virginia, School Of Engineering And Applied Science, Dept. Of Civil Engr.

Patterson, W. J. (2001). SPEED VARIATION, ABSOLUTE SPEED AND THEIR CONTRIBUTION TO SAFETY, WITH SPECIAL REFERENCE TO THE WORK OF SOLOMON. Wellington, New Zealand: Research And Statistics, Land Transport Safety Authority.

R. Elvik, M. C. (2010). Nilsson's Power Model Connecting Seed And Road Trauma: Applicability By Road Type And Alternative Models For Urban Roads. Accident Analysis \& Prevention, 1908-1915.

Reid Ewing, E. D. (2009). The Built Environment And Traffic Safety; A Review Of Empirical Evidence. Journal Of Planning Literature, 347-367.

Sawalha, Z., \& Sayed, T. (2001). EVALUATING SAFETY OF URBAN ARTERIAL ROADWAYS. JOURNAL OF TRANSPORTATION ENGINEERING, 151-158.

Shinar, D. (1998). Speed And Crashes: A Controversial Topic Andan Elusive Relationship Appendix B. Special Report 254: Managing Speed, 221-276.

Solomon, D. (1964). ACCIDENTS On Main Rural Highways Related To Speed, Driver, \& Vehicle. Washington, D.C.: U.S. Department Of Commerce / Bureau Of Public Roads.

Visionzero. (2014). Causes Of Deaths And Serious Injuries On Portland Streets. Portland, Oregon: Portland Bureau Of Transportation.

Vivienne Moore, J. D. (1995). Vehicle Speed And Risk Of Severe Crash. Epidemiology, 258-262. 
Zhibin Li, W. W. (2013). Evaluation Of The Impacts Of Speed Variation On Freeway Traffic Collisions In Various Traffic States. Traffic Injury Prevention, 861-866. 